3 Wagner, H. N., et al., Radiology, 1968, 91, 1168.

4 DeNardo, G. L., et al., New England Fournal of Medicine, 1970, 282, 1334.

5 Nosil, J., et al., Physics in Medicine and Biology, in press.

- Newhouse, M. T., et al., Respiration Physiology, 1968, 4, 141.

7 Loken, M. K., and Westgate, H. D., Fournal of Nuclear Medicine, 1968, 9, 45.

${ }^{8}$ Secker-Walker, R. H., et al., fournal of Nuclear Medicine, 1973, 14, 725.
${ }^{2}$ Isawa, T., Hayes, M., and Taplin, G. V., fournal of Nuclear Medicine, $1971,12,606$

10 Santolicandro, A., and Giuntini, C., to be published.

11 Matthews, C. M. E., and Dollery, C. T., Clinical Science, 1965, 28, 573.

12 Yano, Y., McRae, J., and Anger, H. O., Fournal of Nuclear Medicine, 1970, $11,674$.

13 Colombetti, L. G., et al., fournal of Nuclear Medicine, 1974, 15, 868.

\title{
Changes in Cerebral Blood Flow during a Migraine Attack
}

\author{
J. W. NORRIS, V. C. HACHINSKI， P. W. COOPER
}

British Medical fournal, 1975, 3, 676-684

\section{Summary}

Regional cerebral blood flow studies during a typical prodromal phase of a migraine attack in a young woman showed a global decrease of cerebral blood flow in the carotid artery territory. These studies were repeated during the subsequent headache phase of the same attack and hemispheric blood flow increased considerably. Ergotamine tartrate was then administered intramuscularly which brought definite relief of symptoms but no change in cerebral blood flow. Carotid angiography performed immediately afterwards showed retrograde filling of the proximal portion of the basilar artery, which suggested that the brain stem was the site of hyperperfusion. These findings illustrate certain features underlying both the pathophysiology of migraine itself and its response to ergotamine preparations.

\section{Introduction}

It has been known for many years that migraine headache is associated with changes in the extracranial circulation, while the preheadache or prodromal phase is believed to be due to cerebral vasoconstriction. The observations of Wolff et al. ${ }^{1}$ largely confirmed this apparently paradoxical dissociation between extracranial and intracranial circulation, and, while the therapeutic effect of ergotamine compounds on the extracranial vasculature seems to be established, the response of the cerebral vessels remains unclear.

We recently performed serial estimations of cerebral blood flow (C.B.F.) in a young woman who fortuitously developed a migraine attack before angiography, and the resulting observations throw some light on the pathophysiology of this common though still ill-understood disorder.

\section{Case Report}

An 18-year-old unmarried woman had suffered typical migrainous left-sided hemicrania for two years before admission. The headaches were usually preceded by numbness in the right hand, which spread

MacLachlan Stroke Unit, Department of Neurosciences and Department of Radiology, Sunnybrook Medical Centre, Toronto, Ontario, Canada

J. W. NORRIS, M.D., M.R.C.P., Assistant Professor, Department of Neurosciences

V. C. HACHINSKI, M.D., F.R.C.P.(c.), Lecturer in Neurology

P. W. COOPER, M.D., F.R.C.P.(C.), Assistant Professor, Department of Radiology over the whole right side of the body, including the face, over about 10 minutes. This preheadache phase was often accompanied by a flickering right-sided hemianopia, which started as a tiny spot in the right field of vision and gradually extended over the full half of the visual field. A throbbing left-sided headache then developed, associated with occasional nausea and vomiting, and persisted for several hours. The prodromal phase disappeared rapidly as the headache phase became established. Routine analgesics were normally sufficient to abort the headache and she had never used ergotamine compounds. Because of recent episodes of unduly persistent hemianopia and the alleged, though infrequent, association of underlying arterial anomalies where symptoms occur always on the same side she was admitted for cerebral angiography.

Method. - The intracarotid injection of radioactive ${ }^{133} \mathrm{Xe}$ was used according to the well-established method of Lassen ${ }^{2}$ using a bank of 16 extracranial probes to measure both regional and global (hemispheric) cerebral blood flow. The technique modified for ${ }^{133} \mathrm{Xe}$ was used, ${ }^{3}$ and we injected $2-3 \mu \mathrm{Ci}{ }^{133} \mathrm{Xe}$ through an indwelling catheter in the internal carotid artery. To obtain more regional values than those offered by a strictly lateral array of probes we modified the probe holder to arrange a radial array of detectors. Both stochastic and compartmental values established in our laboratory are similar to those previously published, ${ }^{3}$ all the values for this patient being derived from the initial slope of the clearance curve (C.B.F. initial). Mean arterial blood pressure was continuously monitored via the intracarotid catheter, and blood gas analyses were determined by the Astrup technique performed on blood samples taken by the same route.

Procedure.-During the catheterization of the left internal carotid artery the patient began complaining of her usual prodromal symptoms, with progressive right hemianopia and right-sided numbness. The first regional C.B.F. estimation was then performed. About 15 minutes later the patient developed throbbing left hemicrania and the regional C.B.F. was estimated again. During this time she had increasing malaise and the headache increased in severity. During this second investigation $0.5 \mathrm{mg}$ of intramuscular ergotamine was given. By about 20 minutes after the second procedure none of the previous prodromal symptoms remained, and regional C.B.F. was estimated a third time. The patient's headache had largely disappeared, though a slight left throbbing hemicrania remained. After this procedure left carotid angiography was carried out.

Results.-C.B.F. values during the first procedure (prodromal phase) were uniformly low $\left(37.6 \pm 3.9 \mathrm{ml} 100 \mathrm{~g}\right.$ brain $^{-1}$ min $\left.^{-1}\right)$ and showed no regional differences (fig. 1a). In the second procedure, when the typical throbbing hemicrania was developing, hemispheric blood flow increased considerably $\left(63.3 \pm 6.2 \mathrm{ml} 100 \mathrm{~g}^{-1}\right.$ $\min ^{-1}$ ), but again there were no significant differences in regional values (fig. 1b). The patient was hyperventilating slightly during this phase and arterial carbon dioxide pressure $\left(\mathrm{PaCO}_{2}\right)$ fell so that the flow corrected for the same $\mathrm{PaCO}_{2}$ as in the first estimation was considerably increased ${ }^{3}$ (corrected value at $\mathrm{PaCO}_{2}$ of $5.3 \mathrm{kPa}$ (40 $\left.\mathrm{mm} \mathrm{Hg})=81.0 \mathrm{ml} 100 \mathrm{~g}^{-1} \mathrm{~min}^{-1}\right)$.

Finally, cerebral blood flow values at the third estimation, when the headache had largely disappeared, remained high $(63.5 \pm 10.3 \mathrm{ml}$ $100 \mathrm{~g}^{-1} \mathrm{~min}^{-1}$; fig. 1c) and were even higher if corrected for the $\mathrm{PaCc}_{2}$ (corrected value at $\mathrm{PaCO}_{2}$ of $5.3 \mathrm{kPa}=91.8 \mathrm{ml} 100 \mathrm{~g}^{-1} \mathrm{~min}^{-1}$ ). These results are summarized in the table.

The angiogram recorded at the end of the attack showed retrograde filling of the basilar artery from the posterior communicating artery. The other vessels, including the middle cerebral circulation, were normal (fig. 2). 

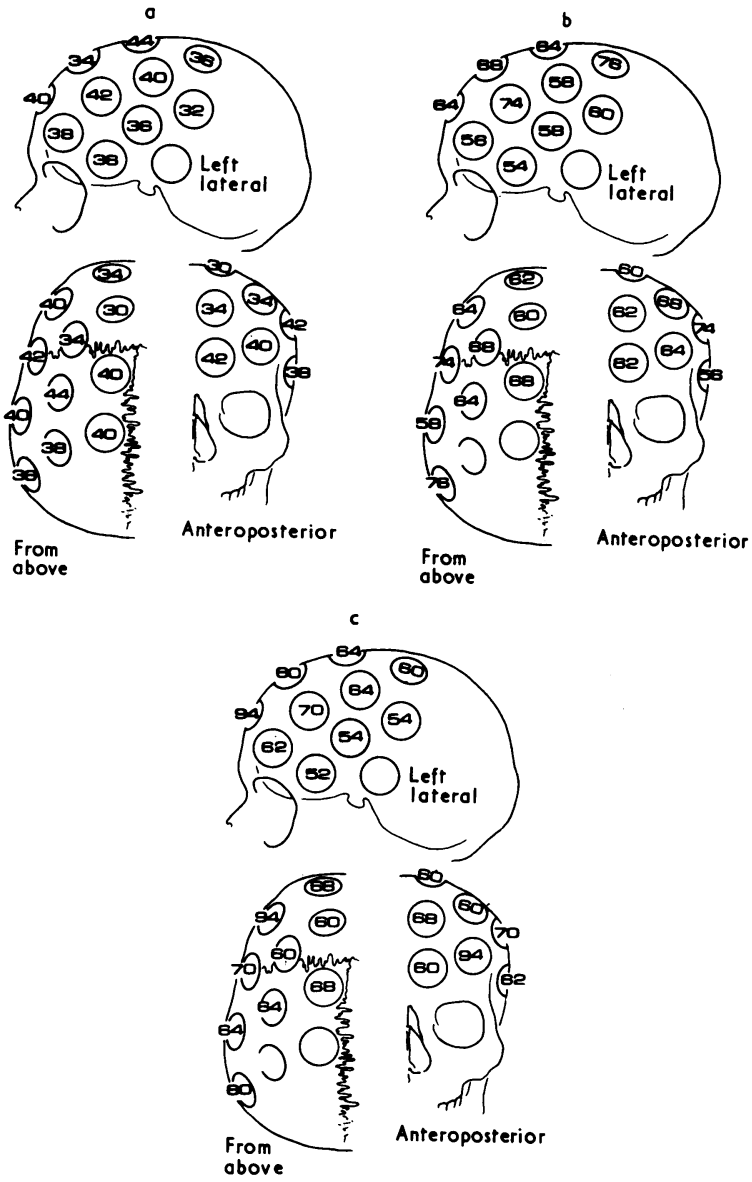

FIG. 1-Regional C.B.F. (ml $\left.100 \mathrm{~g}_{-}^{1} \mathrm{~min}_{-}{ }^{1}\right)$ (a) during prodromal phase; (b) during headache phase; and (c) when headache had largely resolved.

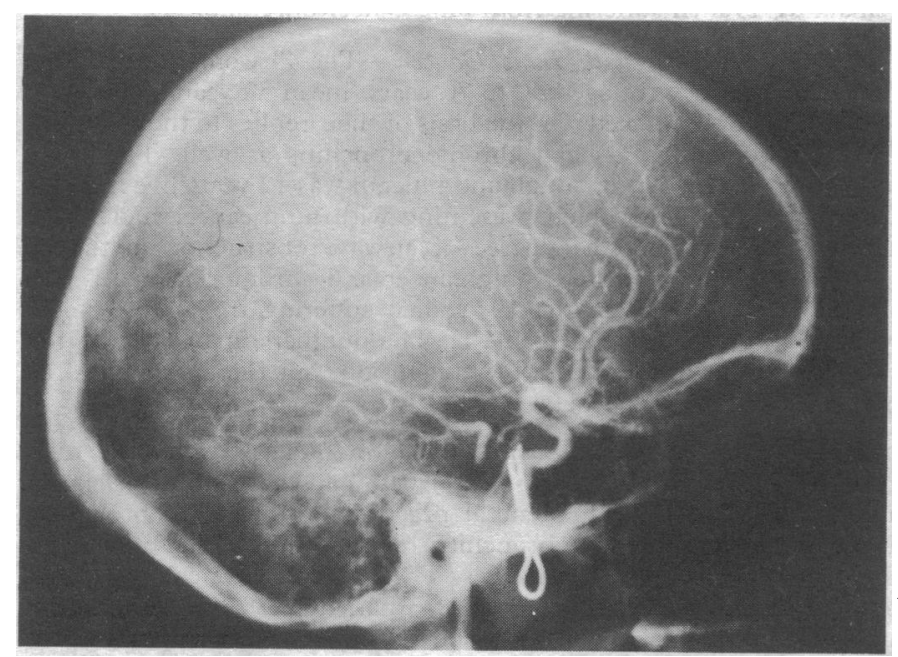

FIG. 2-Left cerebral angiogram showing retrograde filling of vertebrobasilar system in presence of otherwise normal vasculature. (Metallic marker for use during regional cerebral blood-flow estimations is still in situ.)

\section{Discussion}

Our findings confirm those of previous reports, ${ }^{4-8}$ which indicated a glohal decrease in C.B.F. during the prodromal phase of migraine. This decrease was noted even when "cerebral cortex perfusion rate" was evaluated by the inhalation method ${ }^{4}{ }^{6}-a$ clear disadvantage when intracranial and extracranial circulations behave differently. Using the intracarotid technique, however, Skinh $\phi j^{7}$ noted not only a global decrease in flow but also
C.B.F. Values in Three Phases of Migraine Attack

\begin{tabular}{|c|c|c|c|c|}
\hline & & $\begin{array}{l}\text { C.B.F. Initial } \\
\left(\mathrm{ml} 100 \mathrm{~g}^{-1} \mathrm{~min}^{-1}\right)\end{array}$ & $\begin{array}{c}\text { Mean Arterial } \\
\text { Blood Pressure } \\
(\mathrm{mm} \mathrm{Hg})\end{array}$ & $\begin{array}{l}\mathrm{PacO}_{2} \\
(\mathrm{kPa})\end{array}$ \\
\hline $\begin{array}{l}\text { Prodromal phase } \\
\text { Headache phase } \\
\text { After Ergotamine }\end{array}$ & $\begin{array}{l}\cdots \\
\cdots\end{array}$ & $\begin{array}{l}37 \cdot 6 \pm 3 \cdot 9 \\
63 \cdot 3 \pm 6 \cdot 2 \\
63 \cdot 5 \pm 10 \cdot 3\end{array}$ & $\begin{array}{l}115 \\
115 \\
120\end{array}$ & $\begin{array}{l}5 \cdot 3 \\
4 \cdot 5 \\
4 \cdot 1\end{array}$ \\
\hline
\end{tabular}

Conversion: SI to Traditional Units $\mathrm{PaCO}_{2}: 1 \mathrm{kPa} \approx 7.5 \mathrm{~mm} \mathrm{Hg}$.

regional areas of particularly low perfusion which correlated with the clinical findings. The lack of regional differences in our case may indicate that the main site of presumed vasoconstriction was vertebrobasilar rather than in carotid territory since we evaluated only the flow through carotid artery territory.

The increased C.B.F. values at the second estimation indicate not only a restoration of normal perfusion but actually an increased perfusion, possibly the "luxury perfusion" described by Lassen. ' Sampling the cerebrospinal fluid in patients after migraine attacks, Skinh $\phi j^{7}$ found increased lactate values and slightly decreased bicarbonate levels, which indicated that post-ischaemic lactic acidosis was responsible for the cerebral hyperfusion seen in the headache phase.

The continuing increased C.B.F. despite decreasingly severe headache after ergotamine clearly indicates that cerebral perfusion is not involved in the therapeutic effect of this drug, a finding we have already documented in other cases. ${ }^{10}$ Wolff and Graham, ${ }^{11}$ on the other hand, showed that the resolution of migraine headache was accompanied by decreased amplitude of extracranial pulsation. These findings have been confirmed using ${ }^{24} \mathrm{Na}$ clearance rates measuring scalp blood flow. ${ }^{12}$

Duke and Vieth reported filling of the basilar artery after carotid angiography when this procedure was performed during migraine $;^{13}$ angiographic appearances returned to normal after the attack. ${ }^{13}$ They postulated that retrograde filling was due to temporary diversion of blood to vertebrobasilar circulation after middle cerebral artery constriction seen during the same procedure. No such vasoconstriction was seen in the two cases described by Skinh $\phi$, however, nor was it present in our case. The effect is unlikely to be a filling artifact due to the position of the intracarotid catheter since we often perform the procedure yet never see retrograde basilar filling. The prodromal symptoms are compatible with brain-stem location and so this area may have been the site of maximal vasoconstriction and hence maximal reactive hyperperfusion during the headache phase.

When continuing migraine headaches occur in a patient who has sustained a neurological deficit from a previous attack there is hesitation in using ergotamine treatment in case neurological damage is worsened by further cerebral vasoconstriction. The lack of effect of the drug on the cerebral blood flow in this case, however, suggests that no such danger exists.

This work was supported by a grant from the Medical Research Council of Canada, M.R.C. Grant No. MA-5464.

\section{References}

1 Wolff, H. G., Headache and Other Head Pain, p. 241. New York, Oxford University Press, 1963.

2 Lassen, N. A., et al., Neurology, 1963, 13, 719

3 Olesen, J., Paulson, O. B., and Lassen, N. A., Stroke, 1971, 2, 519.

${ }^{4}$ O'Brien, M. D., Lancet, 1967, 1, 1036.

5 Skinhфi, E., and Paulson, O. B., British Medical fournal, 1969, 3, 569.

${ }^{6}$ O'Brien, M. D., Headache, 1971, 10, 139.

7 Skinh $\phi$ j, E., Archives of Neurology, 1973, 29, 95.

${ }^{8}$ Simard, D., and Paulson, O. B., Archives of Neurology, 1973, 29, 207.

9 Lassen, N. A., Lancet, 1966, 2, 1113.

${ }^{10}$ Hachinski, V. C., et al., Canadian fournal of Neurological Sciences, in press.

11 Graham, J. R., and Wolff, H. G., Archives of Neurology and Psychiatry, 1938, 39, 737.

12 Elkind, A. H., Friedman, A. P., and Grossman, J., Neurology, 1964, 14, 14.

${ }^{13}$ Duke, H. T., and Vieth, R. G., Neurology, 1966, 14, 636. 